\title{
Seronegative Antiphospholipid Syndrome with Anti-phosphatidylethanolamine Antibody in a Boy
}

\author{
Takeshi Asano ${ }^{1}$, Hidehiko Narazaki ${ }^{1}$, Kiyohiko Kaizu ${ }^{1}$, \\ Kentaroh Kuwabara ${ }^{2}$, Osamu Fujino ${ }^{1}$ and Yasuhiko Itoh ${ }^{2}$ \\ ${ }^{1}$ Department of Pediatrics, Nippon Medical School Chiba Hokusoh Hospital \\ ${ }^{2}$ Department of Pediatrics, Nippon Medical School
}

\begin{abstract}
Antiphospholipid syndrome (APS) is an autoimmune disease caused by antiphospholipid antibodies. At our institution, APS is diagnosed on the basis of the Sapporo criteria, which consist of thrombosis and recurrent pregnancy-related complications and the following laboratory findings: the presence of lupus anticoagulant, anticardiolipin antibody, or anti- $\beta 2$ glycoprotein 1 antibody. However, we sometimes treat patients we strongly suspect of having APS but who do not satisfy the laboratory criteria. To accommodate such suspected cases, a subtype of APS termed seronegative APS has been proposed. Here, we report on a man with chronic thromobocytopenic purpura since the age of 3 years and multiple cerebral infarctions since the age of 14 years who finally received a diagnosis of seronegative APS with positive antiphosphatidylethanolamine antibodies. (J Nippon Med Sch 2015; 82: 117-120)
\end{abstract}

Key words: antiphosphatidylethanolamine antibody, chronic thrombocytopenia, cerebral infarctions, seronegative antiphospholipid syndrome

\section{Introduction}

Antiphospholipid syndrome (APS) is an autoimmune disease caused by antiphospholipid antibodies; APS is associated with thrombosis and recurrent pregnancy-related complications ${ }^{1}$. At our institution, APS is diagnosed on the basis of the Sapporo criteria ${ }^{1}$, which consist of the above clinical manifestations and the following laboratory findings: the presence of lupus anticoagulant, anticardiolipin antibody, or anti- $\beta 2$ glycoprotein 1 antibody ${ }^{1}$. However, we sometimes treat patients we strongly suspect of having APS but who do not satisfy the laboratory criteria $^{2,3}$. To accommodate such suspected cases of APS, Hughes et al have proposed a subtype of APS termed seronegative APS (SNAPS) ${ }^{3}$. The clinical course of SNAPS is reportedly similar to that of classic APS. In patients with SNAPS, the involvement of several other antigens, ranging from anionic phospholipids to phospholipidprotein complexes and plasma proteins, has been reported $^{1}$. We describe herein a 23-year-old man with thromobocytopenic purpura since the age of 3 years and multiple cerebral infarctions since the age of 14 years who finally received a diagnosis of SNAPS with antiphosphatidylethanolamine (anti-PE) antibodies when he was 21 years old. We obtained informed consent from the patient for publication.

\section{Case Presentation}

A 21-year-old man was re-admitted to our hospital with difficulty speaking and numbness in both the hands and the lower limbs below the knee. At 3 years of age, he had exhibited purpura in the extremities after incidental nontraumatic contact, and immune thrombocytopenic purpura was diagnosed, although bone marrow examination revealed mild hypoplasticity without typical findings of megakaryocytes. He continued to show thrombocytopenia, despite treatment with steroids (prednisolone, $1 \mathrm{mg} / \mathrm{kg}$, or pulse therapy with methylprednisolone) or intravenous gamma globulin or both.

At the age of 14 years, he had complained of numbness in the right hand. On admission at that time physical examination revealed: blood pressure, 152/84 $\mathrm{mm} \mathrm{Hg}$; height, $174.2 \mathrm{~cm}$; and weight, $97.2 \mathrm{~kg}$. Other than the

Correspondence to Takeshi Asano, MD, Department of Pediatrics, Nippon Medical School Chiba Hokusoh Hospital, 1715 Kamagari, Inzai, Chiba 270-1694, Japan

E-mail: VFF13540@nifty.ne.jp

Journal Website (http://www.nms.ac.jp/jnms/) 


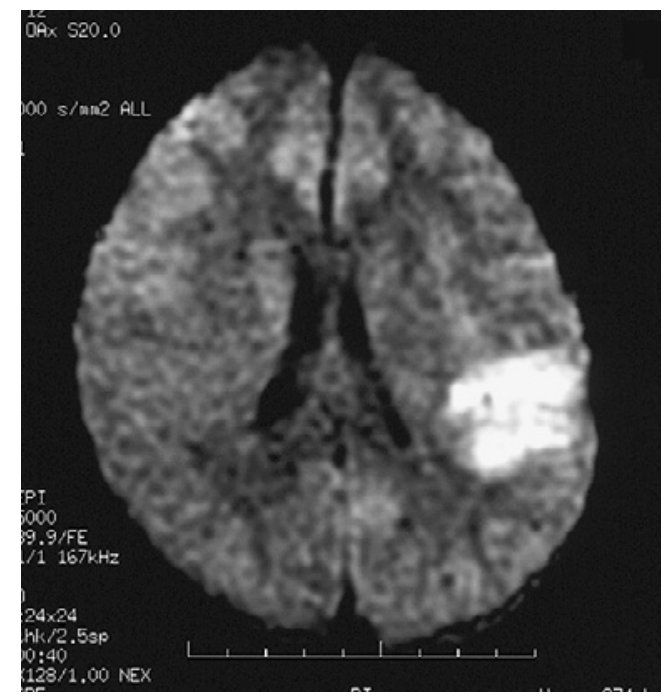

Fig. 1 Diffusion-Weighted MRI findings of first cerebral ischemia attack at 14 years of age. MRI examination at 2 days after cerebral ischemia attack showed high intensity signals in left parietal lobe on DWI, indicating acute cerebral ischemic changes.

numbness of the right hand, no neurological abnormalities were noted. The results of laboratory examination were as follows: C-reactive protein, $0.23 \mathrm{mg} / \mathrm{dL}$; white blood cells, $3,430 / \mu \mathrm{L}$; red blood cells, $379 \times 10^{4} / \mu \mathrm{L}$; hemoglobin, $12.0 \mathrm{~g} / \mathrm{dL}$; hematocrit, $38.5 \%$; platelets, $4.3 \times 10^{4}$ / $\mu \mathrm{L}$; aspartate aminotransferase, $51 \mathrm{IU} / \mathrm{L}$; alanine aminotransferase, $47 \mathrm{IU} / \mathrm{L}$; lactate dehydrogenase, 515 IU/L; alkaline phosphatase, $518 \mathrm{U} / 1$; creatine phosphokinase, $229 \mathrm{U} / 1$; antinuclear antibody, 80x; anti-DNA antibody, <2 IU/mL; lactate dehydrogenase test, negative; Rheumatoid Arthritis test, negative; rheumatoid factor, 16 X; C3, $154 \mathrm{mg} / \mathrm{dL}$; C4, $48.6 \mathrm{mg} / \mathrm{dL}$; CH50, $49 \mathrm{U} / \mathrm{mL}$; perinuclear antineutrophilic cytoplasmic antibody, <13 U/ $\mathrm{mL}$; and cytoplasmic antineutrophilic cytoplasmic antibody, $<13 \mathrm{U} / \mathrm{mL}$. With regard to coagulation, $\beta$ thromboglobulin was $46.0 \mathrm{ng} / \mathrm{mL}(<50 \mathrm{ng} / \mathrm{mL})$, platelet factor 4 was $15.5 \mathrm{ng} / \mathrm{mL}(<20 \mathrm{ng} / \mathrm{mL})$, and coagulation factors VII, VIII, IX, X, XI and XII, and von Willebrand factor showed normal ranges. Anticardiolipin antibody immunoglobulin (Ig) $\mathrm{M}$ was $4 \mathrm{U} / \mathrm{mL}$ (normal: <8), anticardiolipin antibody IgG was $12 \mathrm{U} / \mathrm{mL}$ (normal, $<10 \mathrm{U}$ / $\mathrm{mL}$ ), lupus anticoagulant test was 1.5 (normal, <1.3), and anti- $\beta 2$-glycoprotein I antibodies were $<1.3 \mathrm{U} / \mathrm{mL}$. Diffusion-weighted magnetic resonance imaging (MRI) 2 days after admission showed high-intensity signals in the left parietal lobe, indicating an acute cerebral ischemic change (Fig. 1).

We diagnosed cerebral infarction and treated the pa- tient with concentrated glycerin and edaravone without heparin and discontinued danazol. Transesophageal echocardiography showed no intracardiac thrombosis. By 1 week after admission, the patient's condition had improved, and we discontinued concentrated glycerin and edavavone. However, 2 days later, he had generalized tonic-clonic convulsions for 5 minutes. We therefore readministered concentrated glycerin and edavavone with an anticonvulsant. An electroencephalogram was normal. Multiple, old cerebral infarctions were found with MRI 2 weeks after the convulsions. On discharge, he had no complaint of left hand numbness or speech difficulties but reported needing more time to convert from hiragana (Japanese phonetic symbols) words to Roman letters when typing E-mail on his cellular phone for input.

At the age of 15 years, he again had a cerebral infarction. We strongly suspected APS; however, the Sapporo criteria were not fulfilled because of a lack of persistent positivity for lupus anticoagulant, anticardiolipin, or anti$\beta 2$-glycoprotein I antibodies.

At the age of 21 years, he had a fifth cerebral ischemia attack and was again admitted to our hospital. Diffusionweighted MRI revealed high-intensity signals in the left lobe of the cerebellum, the right subcortical area of the frontal lobe, the right occipital lobe, and the subcortical area of the parietal lobe (Fig. 2a, b, c, d). However, the concentration of anticardiolipin IgG antibodies was $6 \mathrm{U} /$ $\mathrm{mL}$ (normal: $<106 \mathrm{U} / \mathrm{mL}$ ) and that of anti- $\beta 2$-glycoprotein I antibodies were $<1.3 \mathrm{U} / \mathrm{mL}$ (negative). Because we noted looseness of the facial skin, we performed a skin biopsy and chromosomal examination. The skin biopsy showed a lack of elastin, and chromosomal analysis revealed 46, XY, i (7) (q10). Although the body-mass index was high $\left(32.1 \mathrm{~kg} / \mathrm{m}^{2}\right.$; body weight, $98.4 \mathrm{~kg}$; body height, $175 \mathrm{~cm})$, the findings of low total cholesterol $(119 \mathrm{mg} /$ $\mathrm{dL})$, high-density lipoprotein cholesterol $(28 \mathrm{mg} / \mathrm{dL})$, the absence of atherosclerosis on cervical MRI, and a normal echocardiogram indicated that the cause of the stroke was not atherosclerosis.

Because we suspected SNAPS, we measured levels of anti-PE IgG (normal range $<0.36 \mathrm{U} / \mathrm{mL}$ ) and IgM antibodies (normal range $<0.456 \mathrm{U} / \mathrm{mL}$ ) with an enzymelinked immunosorbent assay with or without kininogens using a method previously described ${ }^{4,5}$. The PE was purchased from Avanti Polar Lipids (Birmingham, AL, USA), and phosphatidylserine and alkaline phosphataseconjugated monoclonal antibodies to human IgG and IgM were purchased Sigma Chemical Co). Anti-PE-IgG titer was 0.189 with addition of kininogen for making the 


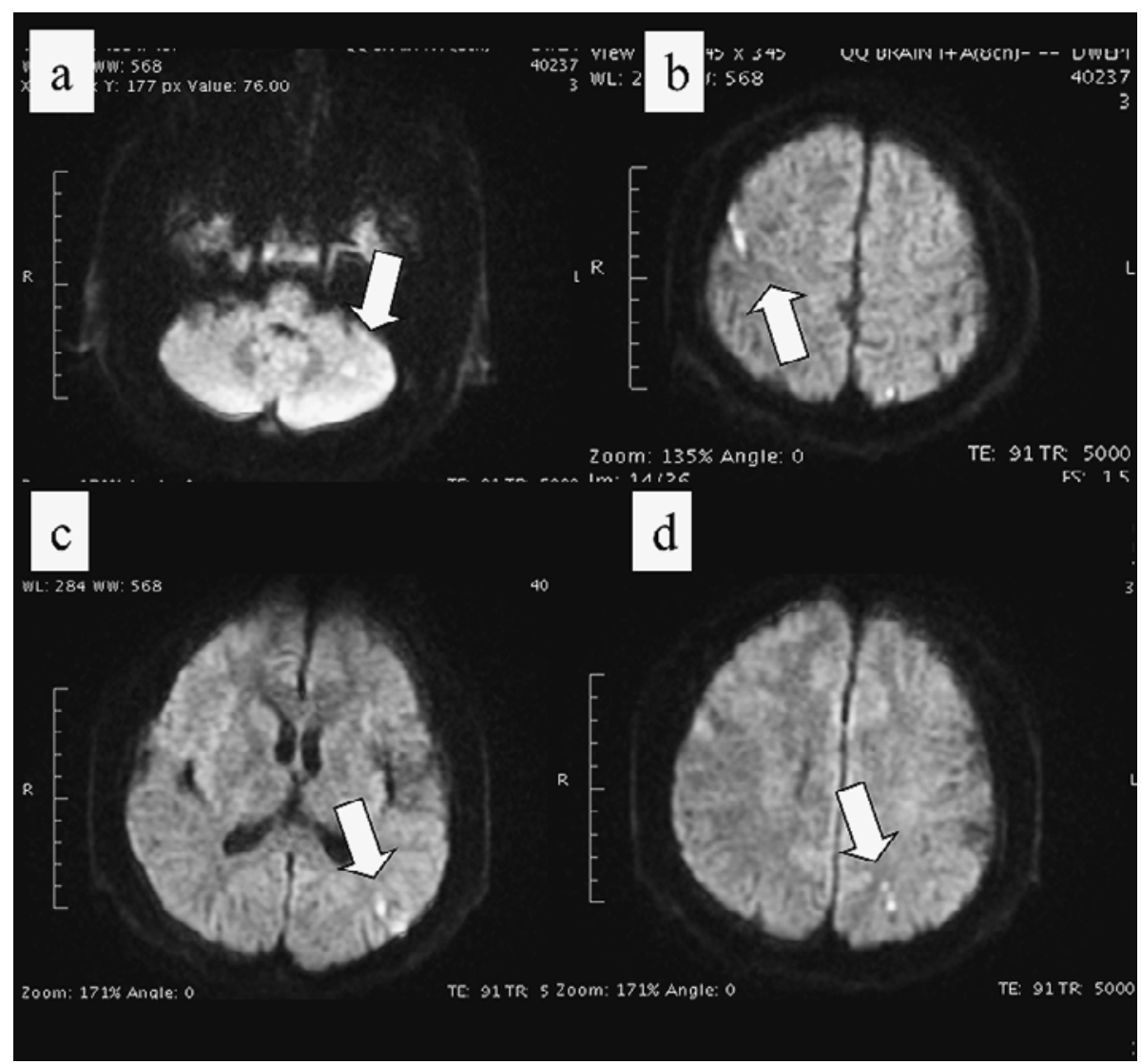

Fig. 2 a. Diffusion-Weighted MRI findings for fifth cerebral ischemia attack at 21 years of age. High intensity in the left lobe of the cerebellum was noted.

b. Diffusion-Weighted MRI findings for fifth cerebral ischemia attack at 21 years of age. High intensity in the right subcortical area of the frontal lobe was noted. c. Diffusion-Weighted MRI findings for fifth cerebral ischemia attack at 21 years of age. High intensity in the right occipital lobe was noted.

d. Diffusion-Weighted MRI findings for fifth cerebral ischemia attack at 21 years of age. High intensity in the sub cortical area of the parietal lobe was noted.

kinninogen-platelet complexs, 0.255 without kininogen, and anti-PE-IgM titer was 0.811 with addition of kininogen and 0.459 without kininogen ${ }^{5}$. We therefore diagnosed serum negative antiphospholipid syndrome ( SNAPS ) with positivity for antiphosphatidylethanolamine antibody.

\section{Discussion}

APS is characterized by diffuse thrombosis, recurrent fetal loss, and the persistent presence of anti-phospholipid antibodies $^{1}$. On the basis of the Sapporo criteria, however, patients with clinical features highly suggestive of APS but who test negative for anti-phospholipid antibodies cannot be classified as having APS; Hughes et al proposed classifying such patients as having seronegative APS (SNAPS) ${ }^{3}$. Several studies have examined the relationship between anti-PE antibody and thrombosis, which is a major clinical feature of $\mathrm{APS}^{6}$. Other studies have focused on anti-PE antibodies as a potential alternative laboratory criterion for diagnosing $\mathrm{APS}^{7}$. In one study, positivity for anti-phospholipid antibodies was confirmed in $58.3 \%$ of patients with SNAPS, with anti-PE antibodies being detected in $30.5 \%$ of these patients ${ }^{8}$. Thus, the value of positivity for anti-PE antibodies in patients with SNAPS remains a controversial topic. We treated a male patient who had had chronic thromobocytopenic purpura from the age of 3 years and multiple cerebral infarctions from the age of 14 years, and in whom SNAPS with anti-PE antibodies was finally diagnosed when he was 21 years old. As mentioned above, several reports have indicated that the clinical manifestations of APS are caused by anti-PE antibodies ${ }^{5}$. PE is found mainly in the inner leaflets of mammalian plasma membranes, and it accounts for $20 \%$ to $50 \%$ of total phospholipids. PE works as an anticoagulant, enhancing activated protein C (APC) activity in blood coagulation 
reactions, downregulating procoagulant function ${ }^{9}$, and inhibiting factor Xa-prothrombin $(\mathrm{PT})^{10}$. Cell surfaceexposed PE plays a major role in translocating protein $\mathrm{C}$ inhibitor proteins across the plasma membrane ${ }^{10}$.

In our patient, anti-PE-IgM was positive only when kininogen was added, so we considered the anti-PE-IgM to be an anti-Kininogen-PE complex-specific antibody. Kininogen-dependent anti-PE antibodies augment thrombin-induced platelet aggregation in vitro, and kininogens bind to platelets and inhibit thrombin-induced platelet aggregation ${ }^{5}$. Therefore, kininogen-dependent anti-PE antibodies may cause thrombosis in vivo by disrupting the normal antithrombotic effects of kininogen ${ }^{5}$.

Cerebral ischemia is a major APS-related event. The biological links between the presence of PE antibodies and the occurrence of thrombosis are unclear. However, the role of PE antibodies in thrombotic events may be due to the prothrombotic activity of a subpopulation of anti-phospholipid antibodies via selective inhibition of the protein $C$ anticoagulant pathway'. This hypothesis is supported by the fact that the presence of $\mathrm{PE}$ enhances the anticoagulant function of APC, and by the ability of anti-phospholipidsy to inhibit APC activity in the presence of $\mathrm{PE}^{9}$.

In conclusion, our study indicates that anti-PE antibody is a marker of SNAPS in patients, including children, with unexplained thrombosis in the absence of anti-anionic phospholipid antibodies and early diagnosis of SNAP using anti-PE antibody might be benefit for the patients with SNAP in terms of prompt treatment.

\section{References}

1. Miyakis S, Lockshin MD, Atsumi T, Branch DW, Brey RL, Cervera R, Derksen RH, DE Groot PG, Koike T, Meroni PL, Reber G, Shoenfeld Y, Tincani A, Vlachoyiannopoulos
PG, Krilis SA: International consensus statement on an update of the classification criteria for definite antiphospholipid syndrome (APS). J Thromb Haemost 2006; 4: 295-306.

2. Kaul M, Erkan D, Sammaritano L, Lockshin MD: Assessment of the 2006 revised antiphospholipid syndrome classification criteria. Ann Rheum Dis 2007; 66: 927-930.

3. Hughes GR, Khamashta MA: Seronegative antiphospholipid syndrome. Ann Rheum Dis 2003; 62: 1127.

4. Sugi T, McIntyre JA: Autoantibodies to kininogenphosphatidylethanolamine complexes augment thrombininduced platelet aggregation. Thromb Res 1996; 84: 97109.

5. Sugi T, Katsunuma J, Izumi S-I, McIntyre JA, Makono T: Prevalence and heterogeneity of antiphosphatidylethanolamine antibodies in patients with recurrent early pregnancy losses. Fertil Steril 1999; 71: 1060-1065.

6. Sanmarco M: Clinical significance of antiphosphatidylethanolamine antibodies in the so-called 'seronegative antiphospholipid syndrome'. Autoimmun Rev 2009; 9: 90-92.

7. Nayfe R, Uthman I, Aoun J, Aldin ES, Merashli M, Khamashta MA: Seronegative antiphospholipid syndrome. Rheumatology 2013; 52: 1358-1367.

8. Conti F, Alessandri C, Sorice M, Capozzi A, Longo A, Garofalo T, Misasi R, Bompane D, Hughes GR, Khamashta MA, Valesini G: Thin-layer chromatography immunostaining in detecting anti-phospholipid antibodies in seronegative anti-phospholipid syndrome. Clin Exp Immunol 2012; 167: 429-437.

9. Smirnov MD, Triplett DT: On the role of phosphatidylethanolamine in the inhibition of activated protein $C$ activity by antiphospholipid antibodies. J Clin Invest 1995; 95: 309-316.

10. Baumgärtner P, Geiger M, Zieseniss S, Malleier J, Huntington JA, Hochrainer K, Edith Bielek E, Stoeckelhuber M, Lauber K, Scherfeld D, Schwille P, Wäldele K, Beyer K, Engelmann B: Phosphatidylethanolamine critically supports internalization of cell-penetrating protein $\mathrm{C}$ inhibitor. J Cell Biol 2007; 179: 793-804.

(Received, August 17, 2014)

(Accepted, November 12, 2014) 